\title{
Topical application of Corchorus olitorius leaf extract ameliorates atopic dermatitis in NC/Nga mice
}

\author{
Satoshi Yokoyama ${ }^{1 *}$, Keiichi Hiramoto', Takahiko Fujikawa' ${ }^{1}$, Hiroya Kondo ${ }^{2}$, Nobuyuki Konishi², Shu Sudo ${ }^{3}$, Makoto Iwashima ${ }^{1}$ \\ and Kazuya Ooi ${ }^{1}$ \\ *Correspondence: s-yoko@suzuka-u.ac.jp

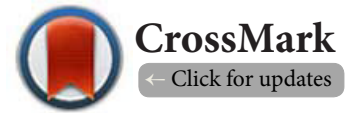 \\ 'Faculty of Pharmaceutical Sciences, Suzuka University of Medical Science, Mie, Japan. \\ ${ }^{2}$ Mie Prefecture Agricultural Research Institute, Matsuzaka, Mie, Japan. \\ ${ }^{3}$ Research and Development Department, Fundamental Research Division, Mikimoto Pharmaceutical \& CO. Ltd., Ise, Mie, Japan.
}

\begin{abstract}
Background: Corchorus olitorius leaves are rich in antioxidants, fatty acids, minerals, vitamins and mucilaginous polysaccharides, and have been used as traditional folk medicine. In a previous study, we found that Corchorus olitorius extract reduced transepidermal water loss, and increased skin hydration in atopic dermatitis (AD)-like lesions in NC/Nga mice. The aim of this study was to investigate the effects of topical application of Corchorus olitorius leaf Extract Excluding the high molecular weight compounds (COEE), on atopic dermatitis (AD), and to elucidate the mechanism underlying the ameliorating effect of COEE on AD-like skin lesions.

Methods: NC/Nga mice housed under specific pathogen-free (SPF) and conventional conditions were each divided into three groups (control, COEE, base cream). At the start of the experiment, the AD scores on the rostral skin of SPF mice and conventional mice were 0 and 8 , respectively. We prepared the COEE cream, and applied it on the rostral skin in NC/Nga mice, and then performed a macroscopic evaluation, an enzyme-linked immunosorbent assay to analyze the plasma levels of immunoglobulin $\mathrm{E}$ (IgE) and histamine and immunohistochemical staining for tryptase, matrix metalloproteinase-9 (MMP-9) and collagen type IV.

Results: After 14 days of treatment with the COEE cream under conventional conditions, the AD scores and plasma IgE concentrations in the COEE group were significantly lower than those in the other groups. Compared to the control and $\mathrm{BC}$ groups, the expression levels of tryptase and MMP-9 were lower, and the degradation of collagen type IV at the basement membrane area was not observed in the COEE group by immunohistochemistry. The mice housed under the SPF conditions were not affected by the test creams.

Conclusions: Our results indicate that COEE may therefore be a useful therapeutic candidate for AD due to its suppression of the plasma IgE level and degranulation of mast cells.
\end{abstract}

Keywords: Atopic dermatitis, Corchorus olitorius, immunoglobulin E, histamine, tryptase

\section{Introduction}

The epidermis serves as the first line of defense against invading pathogens and allergens [1]. In atopic dermatitis (AD)-like skin lesions, this epidermal skin barrier is disrupted, which is reflected by increased transepidermal water loss (TEWL), as well as reduced hydration of the stratum corneum. Further, the penetration of pathogens and allergens through the skin is facilitated, which can trigger an inflammatory response via synergistic immunological mechanisms [2]. The inflammatory response increases the plasma immunoglobulin $\mathrm{E}(\mathrm{IgE})$ levels, and under inflammatory conditions, an increased number of mast cells can be found in the dermis, which play a crucial role in the pathophysiology of AD. In AD-like skin lesions, allergen induced cross-linking of lgE-binding sites on mast cells is followed by an explosive release of granular mediators. Thus, mast cells release histamine and tryptase into the extracellular matrix during the degranulation process [3]. Excess histamine causes an inflammatory response and pruritus. Pruritus is the most disturbing symptom of AD. Severe pruritus often leads to an "itch-scratch" cycle that may compromise the epidermal barrier, resulting in TEWL elevation and reduced skin hydration $[4,5]$. One of the reasons for the TEWL elevation is the disruption of the basement membrane [6]. The basement membrane is mainly composed of collagen type IV. Disruption of this collagen is related to the tryptase activity. Tryptase is also released from mast cells, and activates matrix metalloproteinase-9 (MMP-9). MMP-9 also degrades collagen type IV [7]. The degradation of collagen type IV induces the breakdown of the basement membrane, and may increase the TEWL. Thus, it presumed that suppressing the degranulation of mast cells would prevent the disruption of the skin barrier function.

Corchorus olitorius is a plant from the Tiliaceae family from the Mediterranean region, the leaves of which are rich in antioxidants, such as vitamin $C$, vitamin $E, \beta$-carotene, a-tocopherol, glutathione and phenols [8]. The leaves also contain fatty acids, minerals, other vitamins and mucilaginous 
Yokoyama et al. Dermatology Aspects 2014,

polysaccharides, and have been used as traditional folk medicine. We previously developed a cream formulation containing Corchorus olitorius leaf Extract Excluding high molecular weight compounds (COEE) like polysaccharides, and investigated the skin hydration effect of this cream.

$\mathrm{NC} /$ Nga mice were established as an inbred strain from Japanese fancy mice in 1957, and have recently been shown to spontaneously develop AD-like dermatitis with IgE hyperproduction under air-uncontrolled, conventional circumstances [9]. Our previous study showed that the COEE cream increased the skin hydration and reduced the TEWL on the AD-like skin lesions in NC/Nga mice, and protected the skin barrier function in these mice. Further, the COEE cream improved the $A D$ symptoms, and suppressed the increases in the $A D$ score in $\mathrm{NC} / \mathrm{Nga}$ mice [10]. We hypothesized that COEE might be effective against $A D$. This study was performed to evaluate the effects of COEE on the development of AD-like skin lesions in NC/Nga mice by measuring the symptom severity, plasma $\mathrm{IgE}$ and histamine concentrations and by performing an immunohistochemical examination. The effect of COEE might be associated with its suppression of the immunological and inflammatory response in AD.

\section{Materials and methods \\ Experimental animals}

Six-week-old male NC/Nga mice were purchased from Japan SLC Inc. (Shizuoka, Japan). The mice were divided into two groups: specific pathogen-free (SPF; $n=9$ ) and conventional $(n=15)$ group. In each group, the mice were further divided into three groups: control, COEE and base cream (BC) $(n=3$ in each SPF group, $\mathrm{n}=5$ in each conventional group). The mice in the conventional group were housed under conventional conditions, while those in the SPF group were housed under SPF conditions. All mice were individually housed throughout the experiment (therefore, under social isolation stress) with one mouse/plastic cage lined with wood chips. The animals were acclimatized under standard conditions with a 12-h light: dark cycle, constant temperature of $25 \pm 2^{\circ} \mathrm{C}$ and $50 \pm 10 \%$ relative humidity for seven days in the animal research facility prior to commencing experimentation. All mice were allowed access to water and food ad libitum. The experimental protocol for this study was approved by the animal care regulations of Osaka City University Medical School.

\section{Preparation of the COEE}

Dry powdered Corchorus olitorius leaves were purchased from Mie Prefecture Agricultural Research Institute. This sample was extracted three times for $48 \mathrm{~h}$ at room temperature using acetone. To isolate the highly polar fraction, the residue was further extracted with methanol: $\mathrm{H}_{2} \mathrm{O}(2: 1)$ at $85^{\circ} \mathrm{C}$ under reflux conditions for three hours. After filtration and freeze-drying, this extract was used for the formulation of the COEE cream. The COEE produced by our extraction methods described above contains few compounds over 1,000 molecular weight.
However, various phenols and fatty acids are contained in the COEE, which was confirmed by thin-layer chromatography.

\section{Formulation of the COEE cream}

The COEE cream contained $0.2 \%$ extract of Corchorus olitorius leaf in the base cream, with the $\mathrm{pH}$ adjusted to approximately 6.0. The other ingredients, in order of decreasing concentration, were water, glyceryl tri(2-ethylhexanoate), acrylic acid, alkyl methacrylate copolymer, 1,3-butanediol, L-arginine, 1,2-dihydroxypentane, 2-hydroxyethyl phenyl ether and hydrogenated egg yolk phospholipids (Table 1).

Table 1. The ingredients in COEE cream and base cream.

\begin{tabular}{l|ll}
\hline \multirow{2}{*}{ Ingredients } & \multicolumn{2}{|c}{ (\%) } \\
\cline { 2 - 3 } COEE & COEE cream & Base cream \\
\hline Water & 0.2 & -- \\
Glyceryl tri(2-ethylhexanoate) & 52.1 & 52.3 \\
Acrylic acid-alkyl methacrylate copolymer & 16.0 & 18.0 \\
1,3-butanediol & 18.0 & 16.0 \\
L-arginine & 6.8 & 6.8 \\
1,2-dihydroxypentane & 3.5 & 3.5 \\
2-hydroxyethyl phenyl ether & 3.0 & 3.0 \\
Hydrogenated egg yolk phospholipids & 0.3 & 0.3 \\
\hline
\end{tabular}

COEE: Corchorus olitorius leaf extract excluding the high molecular weight compounds

Application of formulations to the rostral skin of mice The skin on the back of each mouse was shaved with electric clippers and used as a sensitizing area. The rostral skin of the COEE group mice was treated with $0.1 \mathrm{~g}$ of COEE cream once a day. This treatment was continued for 14 days. The rostral skin of the BC group mice was treated with $0.1 \mathrm{~g}$ of the base cream without COEE.

\section{Evaluation of the severity of $\mathrm{AD}$}

The lesions on the rostral skin were assessed macroscopically according to the following four symptoms: erythema, edema, erosion and dryness, and the sum was considered to be the individual's score (0: no symptoms; 1 , mild; 2 , moderate; 3 : severe) $[9,11]$. At the start of this experiment, the AD score in the SPF and conventional groups were 0 and 8, respectively. Then, the skin lesions were examined and the severities were scored 14 days after the application of each formulation. These visual assessments were performed by at least two independent investigators. The changes in the rostral skin symptoms of the $\mathrm{NC} / \mathrm{Nga}$ mice were evaluated by viewing photographs of the mice.

\section{Isolation of rostral skin samples and blood}

Mice were sacrificed 14 days after initiating the application of 
Yokoyama et al. Dermatology Aspects 2014,

the test creams. Approximately $1 \mathrm{~mL}$ of blood was withdrawn from the heart. Skin biopsies obtained from the rostral skin were fixed in phosphate-buffered saline containing $4 \%$ paraformaldehyde.

Analysis of the plasma IgE and histamine concentrations The plasma was fractionated from collected blood samples by centrifugation at $10,000 \times g$ for $10 \mathrm{~min}$ at $4^{\circ} \mathrm{C}$. The supernatant was used for the lgE and histamine assays. The plasma IgE and histamine concentrations were measured using an enzyme linked immunosorbent assay kit (YamasaShoyu Co., Ltd., Chiba, Japan and Bertin Pharma, Montigny le Bretonneux, France, respectively) according to the manufacturers' instructions. The optical density was measured with a microplate reader (Molecular Devices, Sunnyvale, CA).

Histopathological and immunohistochemical analysis Fixed skin specimens were embedded in frozen Tissue Tek OCT compound, and cut into $5 \mu \mathrm{m}$ thick sections. Thin sections were stained with hematoxylin-eosin and analyzed histologically to evaluate the degree of inflammation. Other thin sections, after being washed with phosphate-buffered saline (PBS), were incubated with a goat anti-mast cell tryptase (1:50) polyclonal antibody (Santa Crus Biotechnology Inc., Santa Cruz, CA), rabbit anti-MMP-9 (1:50) polyclonal antibody (Abnova, Taipei, Taiwan) or a rabbit anti-collagen type IV (1:100) polyclonal antibody (Abcam, Tokyo, Japan) overnight at $4^{\circ} \mathrm{C}$. The specimens were then washed in PBS, and were incubated at room temperature for $2 \mathrm{~h}$ with TRITC conjugated anti-goat immunoglobulin or FITC-conjugated anti-rabbit immunoglobulin (1:30; DakoCytomation, Denmark). The expression of tryptase, MMP-9 and collagen type IV was evaluated immunohistochemically under fluorescence microscopy using Image J software program.

\section{Statistical analysis}

All data are presented as the means \pm SD. The comparison of the $A D$ scores was performed using the Wilcoxon rank-sum test. Comparisons among three groups were performed using a one-way analysis of variance (ANOVA), with Tukey's test for multiple comparisons used for the post-hoc analysis. Values of $p<0.05$ were defined as statistically significant.

\section{Results}

\section{Evaluation of the severity of AD}

There were no symptoms associated with AD after the 14 days of application on the skin of the SPF mice. On the other hand, the conventional mice in the control group after 14 days exhibited marked symptoms characteristic of $A D$, including edema, erythema and hemorrhage of their rostral skin. The dermal symptoms were ameliorated in the COEE group after the 14 day application (Figure 1).

At the start of this experiment, the AD scores of SPF group and conventional group were 0 and 8, respectively. After the
14 days of application of the cream, the AD scores of the SPF groups did not change. In contrast, the symptoms or dermatitis in the conventional control mice significantly increased in severity $(p<0.05)$, while the AD score in the conventional COEE group significantly decreased $(p<0.05)$. There was no significant change in the $A D$ score in the $B C$ group after the application compared to the value at baseline (Figure 2).

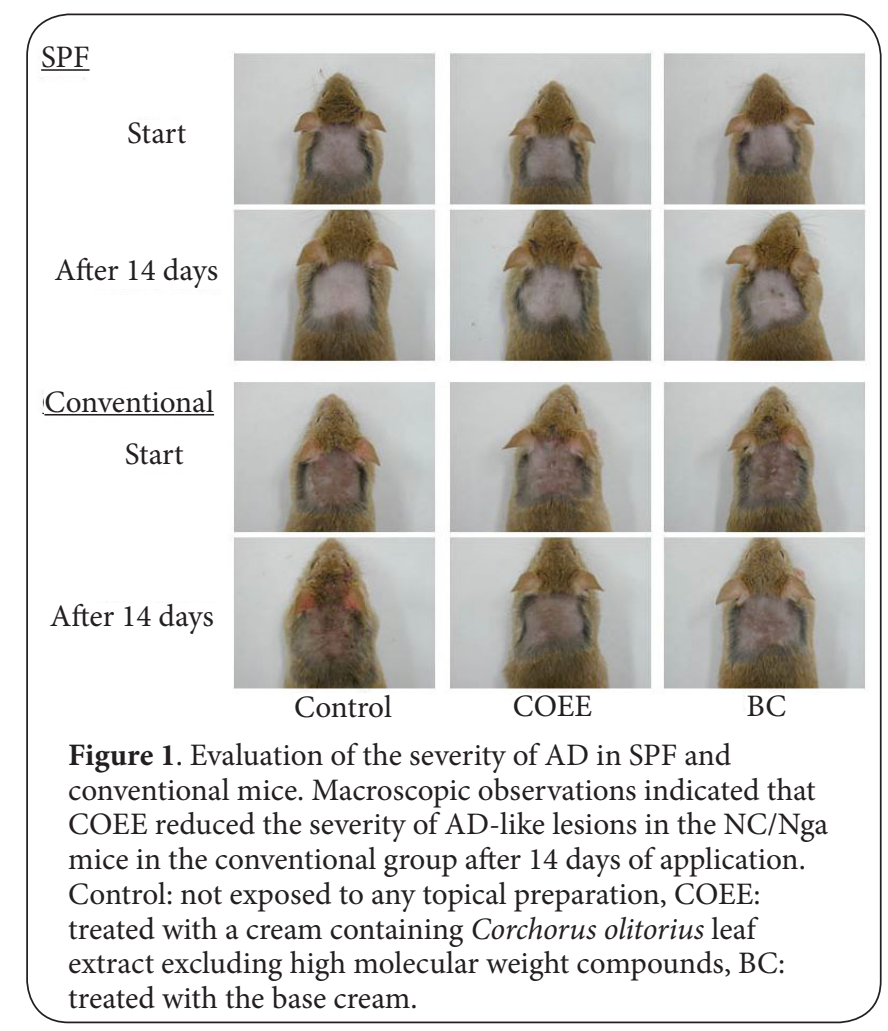

Histopathological changes after 14 days of applications The morphological findings are shown in Figure 3. Histopathological changes were not detected between the control (Figure 3a), COEE (Figure 3b) and BC (Figure 3c) groups under the SPF condition. In the conventional control group (Figure 3d), notable acanthosis, hyperplasia of the epidermis, ulceration and infiltration of large numbers of lymphocytes to the dermis were evident. In the conventional BC group (Figure 3f), the severity of dermatitis was also exacerbated after 14 days. On the other hand, the hyperplasia and thickening of the epidermis were obviously suppressed, and there was minimal inflammatory cell infiltration in the conventional COEE group (Figure 3e).

\section{Plasma IgE and histamine concentrations}

No plasma samples showed evidence of hemolysis, as assessed by visually examining the color. There were no significant differences in the plasma IgE concentrations among the control, COEE and BC groups under the SPF condition. On the 


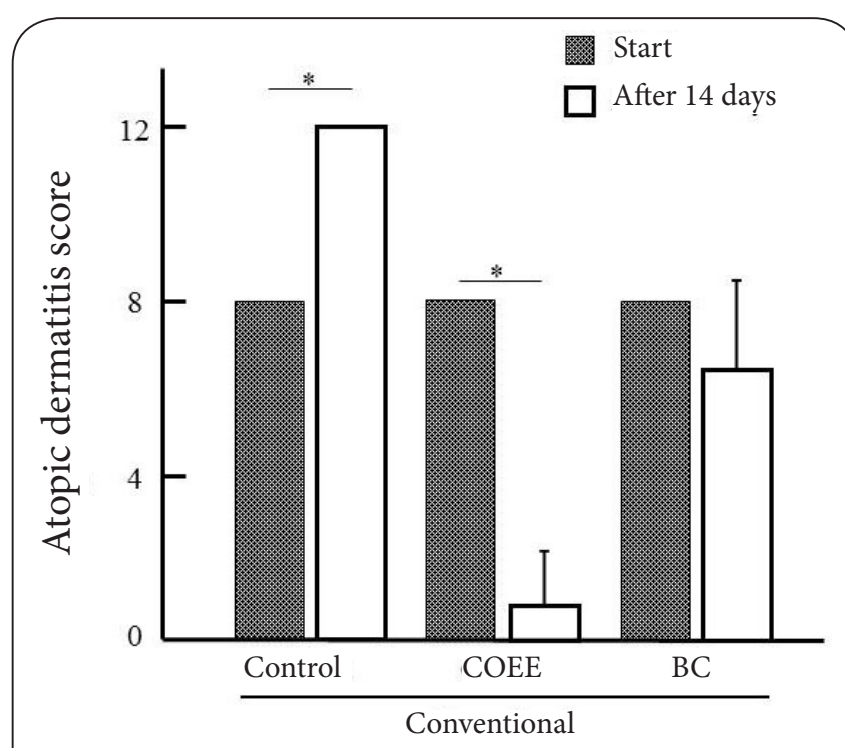

Figure 2. The effects of COEE on the atopic dermatitis score for the rostral skin of NC/Nga mice under conventional conditions. The scoring was performed at the start of the experiment and after 14 days of application. The values represent the means \pm S.D. ( $n=3$ in each $S P F$ group, $n=5$ in each conventional group). Control: not exposed to any topical preparation, COEE: treated with a cream containing Corchorus olitorius leaf extract excluding high molecular weight compounds, BC: treated with the base cream, ${ }^{*}: p<0.05$ compared with the values at the start of the experiment (Wilcoxon rank-sum test).

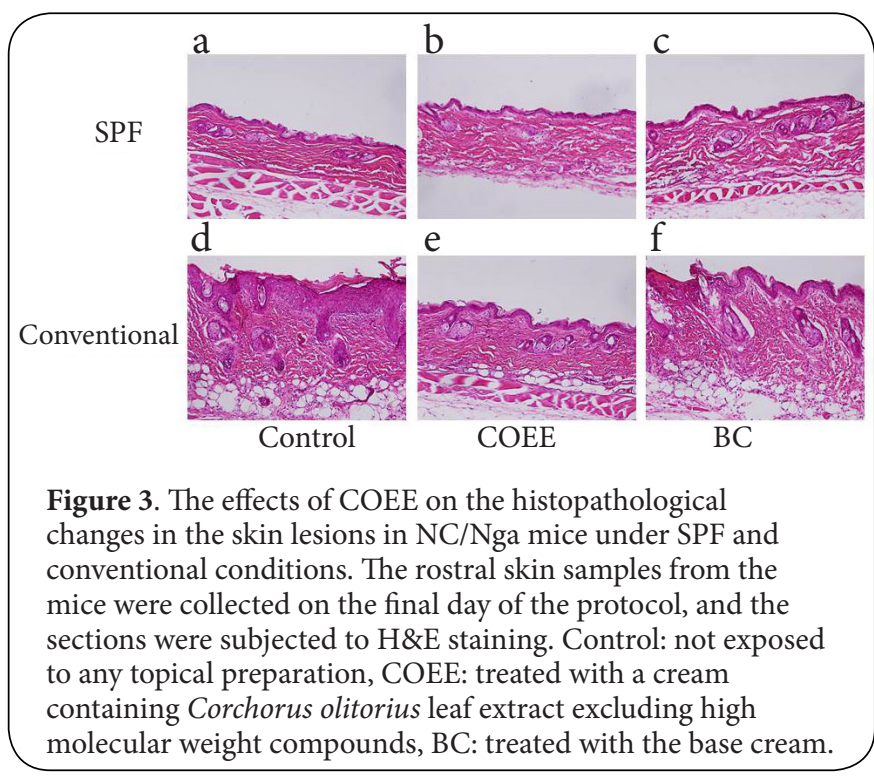

other hand, the plasma IgE concentrations of the conventional control and $B C$ groups were markedly increased. However, the plasma IgE concentration in the conventional COEE group was significantly lower compared to that in the conventional control or BC group (Figure 4).

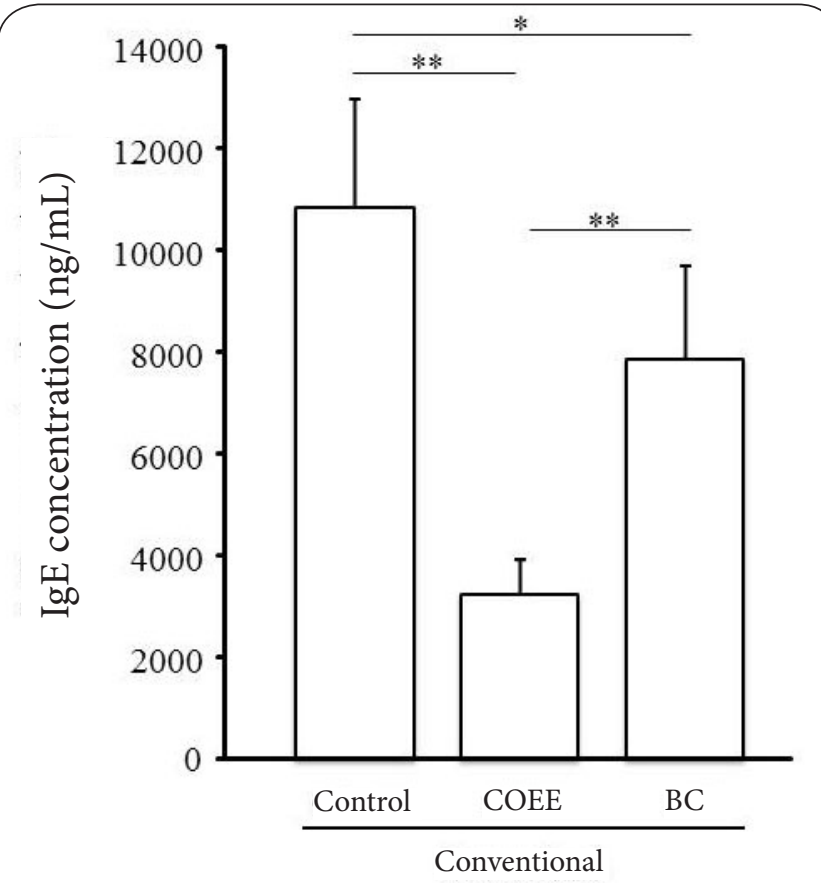

Figure 4. The effects of COEE on the plasma IgE concentrations in NC/Nga mice housed under conventional condition. The topical application of COEE significantly reduced the IgE concentration under conventional conditions. The data are presented as the means \pm S.D. ( $\mathrm{n}=3$ in each SPF group, $\mathrm{n}=5$ in each conventional group). ${ }^{*}: p<0.05,{ }^{* *}: p<0.01$ (one-way ANOVA followed by Tukey's test). Control: not exposed to any topical preparation, COEE: treated with a cream containing Corchorus olitorius leaf extract excluding high molecular weight compounds, BC: treated with the base cream.

Figure 5 shows the plasma histamine concentrations in the conventional groups. The plasma histamine concentrations of the SPF group were equal among the control, COEE and $\mathrm{BC}$ groups. Under the conventional condition, the plasma histamine concentrations in the control, COEE and BC groups were all higher than those under the SPF condition. However, the plasma histamine concentration in the conventional COEE group was significantly lower than that in the conventional control group, and tended to be lower than that in the BC group.

Immunohistochemical examination of the tryptase, MMP-9 and collagen type IV expression in the skin

Figures 6 and 7 show photographs of the rostral skin sections stained for tryptase and MMP-9 in the epidermis of the conventional and SPF mice. No expression of tryptase or MMP9 in the SPF group was observed. Under the conventional condition, the expression levels of tryptase and MMP-9 in the control group were clearly increased. In the conventional BC group, the expression levels of tryptase and MMP-9 were lower than those in the conventional control group, but were still elevated compared to the SPF group. The expression 


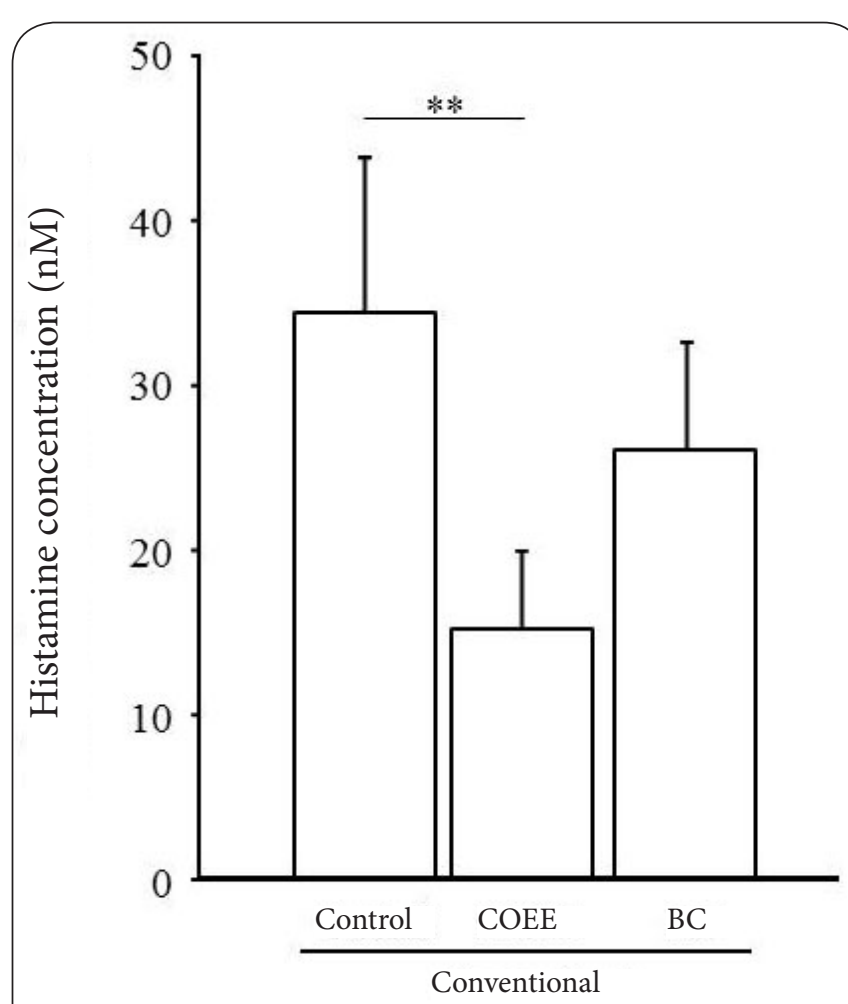

Figure 5. The effects of COEE on the plasma histamine concentrations in $\mathrm{NC} / \mathrm{Nga}$ mice housed under conventional condition. The topical application with COEE significantly reduced the histamine concentration under conventional conditions. The data are presented as the means \pm S.D. $(n=3$ in each SPF group, $\mathrm{n}=5$ in each conventional group). ${ }^{* *}: p<0.01$ (one-way ANOVA followed by Tukey's test). Control: not exposed to any topical preparation, COEE: treated with a cream containing Corchorus olitorius leaf extract excluding high molecular weight compounds, BC: treated with the base cream.

levels of tryptase and MMP-9 were markedly reduced in the conventional COEE group, and were similar to those of the SPF group.

Under the SPF condition, the expression of collagen type IV was observed in all of the mice. On the other hand, the expression level of the collagen type IV in the conventional control group and conventional BC group was lower than that in the SPF groups. In the conventional COEE group, the expression level of the collagen type IV was similar to that in the SPF group (Figure 8).

\section{Discussion}

In this study, we investigated whether COEE could ameliorate the severity of AD-like skin lesions in NC/Nga mice. Our results showed that topical treatment of the rostral AD-like skin of NC/Nga mice with the COEE cream improved the AD score and symptoms characteristic of AD (hyperplasia and a thickened epidermis). It seemed that topical application of the base cream prevented the aggravation of $A D$, and

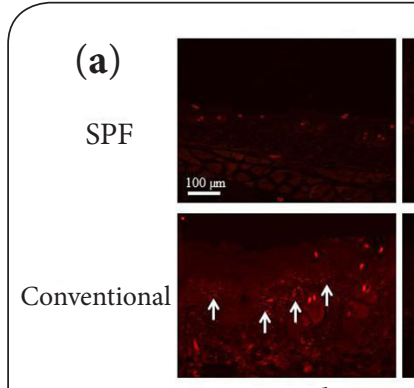

Control

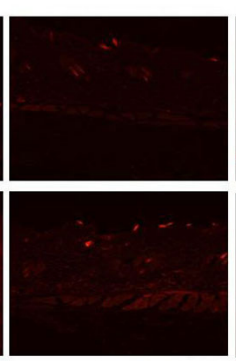

COEE

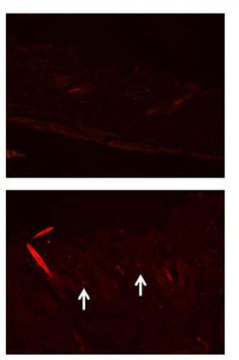

$\mathrm{BC}$ (b)

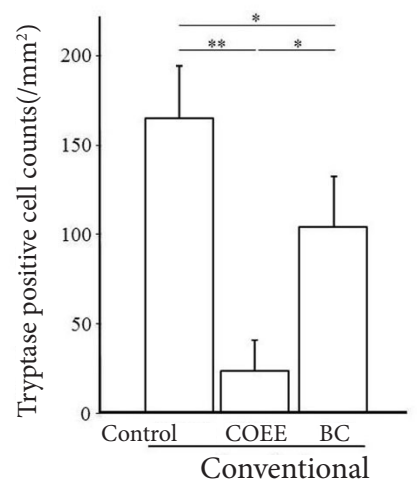

Figure 6. The results of the immunohistochemical analysis of the tryptase expression in the skin of NC/Nga mice.

(a) The tryptase expression in the conventional COEE group was decreased compared with that in the conventional control and $\mathrm{BC}$ groups. Control: not exposed to any topical preparation, COEE: treated with a cream containing Corchorus olitorius leaf extract excluding high molecular weight compounds, BC: treated with the base cream. The scale bar represents $100 \mu \mathrm{m}$.

(b) Comparison of tryptase positive cell counts among three groups in conventional conditions. ${ }^{*}: p<0.05,{ }^{* *}: p<0.01$ (oneway ANOVA followed by Tukey's test). when COEE was addedto the base cream, it improved the $A D$ symptoms. The plasma IgE levels are generally elevated in AD. IgE can bind the high-affinity lgE receptor, and leads to mast cells degranulation and their secretion of histamine and tryptase [12]. The COEE cream led to a reduction of the plasma IgE level and suppressed the histamine and tryptase secretion from mast cells, and also inhibited the disruption of collagen type IV by MMP-9.

IgE production involves the type 2 helper T cell (Th2)biased response. Th2 cells play a central role in the allergic inflammatory response. The Th2 cytokines, such as interleukin (IL)-4 and IL-13, stimulate the B cells and induce the production of allergen-specific lgE [13]. It is accepted that some natural dietary substances have the ability to suppress the elevation of the IgE level during the inflammatory response. Previous studies demonstrated that Konjac glucomannnann was able to prevent the increase in the plasma IgE and epsilon germline transcript levels due to its inhibition of the class-switching of B cells [14]. Fucoidan is also a natural dietary substance, 


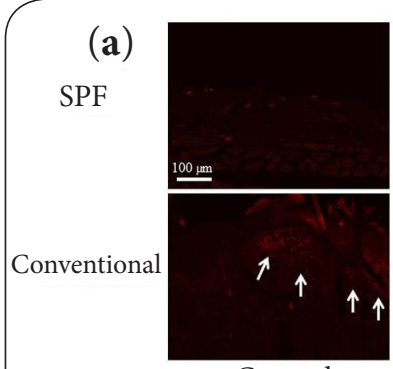

Control

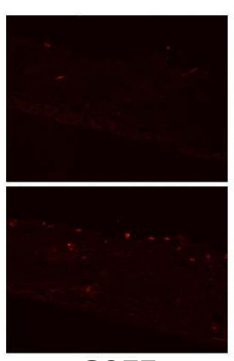

COEE

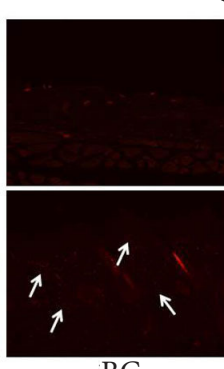

$\mathrm{BC}$ (b)

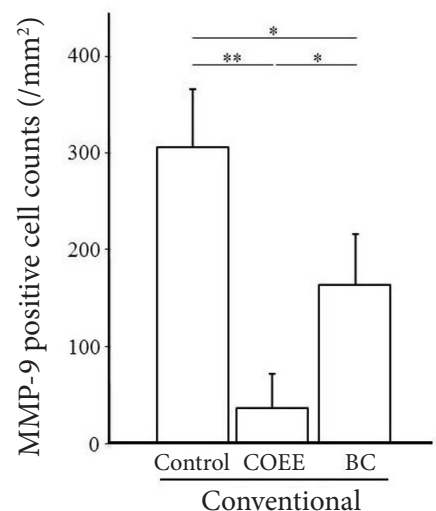

Figure 7. The results of the immunohistochemical analysis of the MMP-9 expression in the skin of NC/Nga mice.

(a) The MMP-9 expression in the conventional COEE group was decreased compared with that in the conventional control and BC groups. Control: not exposed to any topical preparation, COEE: treated with a cream containing Corchorus olitorius leaf extract excluding high molecular weight compounds, BC: treated with the base cream. The scale bar represents $100 \mu \mathrm{m}$.

(b) Comparison of MMP-9 positive cell counts among three groups in conventional conditions. ${ }^{*}: p<0.05,{ }^{* *}: p<0.01$ (one-way ANOVA followed by Tukey's test).

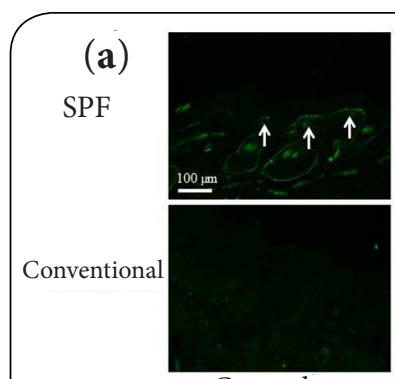

Control
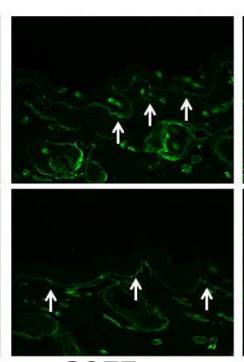

COEE

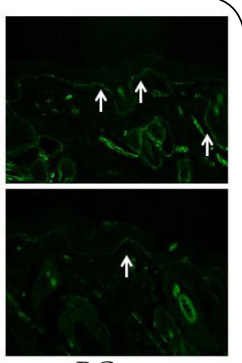

$\mathrm{BC}$ (b)

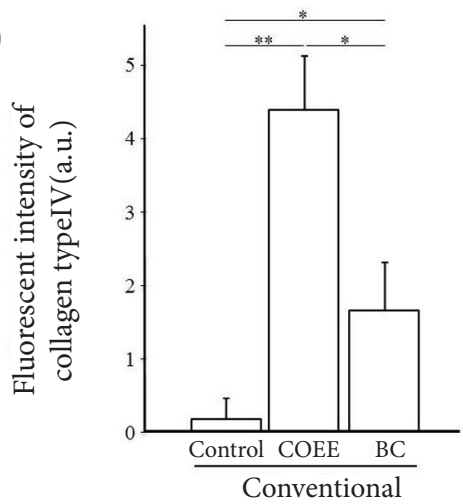

Figure 8. The results of the immunohistochemical analysis of the collagen type IV expression in the skin of NC/Nga mice. (a) The collagen type IV expression in the conventional control and $\mathrm{BC}$ groups was decreased compared with that in the conventional COEE group. Control: not exposed to any topical preparation, COEE: treated with a cream containing Corchorus olitorius leaf extract excluding high molecular weight compounds, BC: treated with the base cream. The scale bar represents $100 \mu \mathrm{m}$.

(b) Comparison of fluorescent intensity of collagen type IV among three groups in conventional conditions. a.u.: arbitrary unit, $^{*}: p<0.05,{ }^{* *}: p<0.01$ (one-way ANOVA followed by Tukey's test).

and reduces the $\lg E$ production by preventing the activation of the nuclear factor kappa B-mediated pathways by CD40 [15]. Our findings implied that there might be some natural substance(s) contained in the COEE thatsuppress the class switching of B cells. Konjacglucomannnann and fucoidan were administered orally, but COEE was administered by topical application. However, the oral administration of COEE may also have the ability to attenuate AD symptoms, and this should be evaluated in future studies.

Corchoionoside A, B and (6S, 9R) roseoside are ionone glucosides contained in the leaves of Corchorus olitorius. These compounds were previously shown to inhibit the histamine release from rat peritoneal exudate cells induced by the antigen-antibody reaction [16]. The same effect was found in our in vivo study. Histamine, a potent mediator of inflammatory responses, induces pruritus, leading to the "itchscratch" cycle [17], and upregulates MMP-9 production [18]. Tryptase, which is also an inflammatory marker released from mast cells, either alone or in conjunction with the activation of MMPs, can participate in extracellular matrix damage and possibly in the destruction of the basement membrane [7]. Our investigation revealed that the COEE suppressed the release of histamine and tryptase from mast cells and prevented the degradation of skin tissue.

Another possible mechanism was suggested by the fact that the extract from C. Olitorius leaf has antioxidant properties [19]. Corchorus olitorius leaf was found to contain high quantities of antioxidant molecules such as phenols, flavonoids, ascorbic acid and carotenoids [8]. Reactive oxygen species (ROS) are generally released from neutrophils, macrophages and eosinophils during the inflammatory response. Although ROS play a role in excluding allergens, greatly increased levels of ROS contribute to the development of skin tissue disruption, and increase the severity of AD [20]. Mast cells stimulated by lgE produce endogenous ROS, and these ROS have important functions in regulating various mast cell 
Yokoyama et al. Dermatology Aspects 2014,

responses, including degranulation, leukotriene secretion and cytokine production, which lead to the disruption of the skin's structure [21]. Thus, the antioxidants contained in COEE might lead to the suppression of AD. Moreover, COEE contains fatty acids. Fatty acids have the ability to exert antiinflammatory effects $[\mathbf{2 2 , 2 3 ]}$. Therefore, the phenols and fatty acids included in COEE may have ameliorated the aggravation of $A D$ in NC/Nga mice.

The mechanism by which the COEE suppresses IgE production remains unclear, and further studies are needed on this point, but our study revealed that COEE suppressed the IgE production and attenuated the aggravation of AD. The limitations of this study are related to the fact that it was an animal study with low numbers, and because it is directly translate theconclusions drawn in mice to humans. However, with regard to the animal numbers, we performed the same experiments three times, and confirmed the reproducibility. Therefore, we believe that our results have high reliability. Further, the COEE cream can be feasibly and safely administered topically, because there was no influence of the COEE cream on the AD score or plasma inflammatory marker levels in SPF mice.

\section{Conclusions}

These results suggest that COEE may be a useful therapeutic candidate for AD. However, the effects of the COEE on human $A D$ still remain to be clarified and should be investigated in further studies. We are hoping to elucidate and clarify this issue in the future.

\section{Competing interests}

The authors declare that they have no competing interests.

Authors' contributions

\begin{tabular}{|l|c|c|c|c|c|c|c|c|}
\hline Author's contributions & SY & KH & TF & HK & NK & SS & MI & KO \\
\hline Research concept and design & $\checkmark$ & $\checkmark$ & $\checkmark$ & $\checkmark$ & $\checkmark$ & $\checkmark$ & $\checkmark$ & $\checkmark$ \\
\hline $\begin{array}{l}\text { Collection and/or assembly } \\
\text { of data }\end{array}$ & $\checkmark$ & $\checkmark$ & $\checkmark$ & $\checkmark$ & $\checkmark$ & $\checkmark$ & $\checkmark$ & -- \\
\hline $\begin{array}{l}\text { Data analysis and } \\
\text { interpretation }\end{array}$ & $\checkmark$ & $\checkmark$ & -- & -- & -- & -- & -- & -- \\
\hline Writing the article & $\checkmark$ & $\checkmark$ & -- & -- & -- & -- & -- & -- \\
\hline Critical revision of the article & $\checkmark$ & $\checkmark$ & -- & -- & -- & -- & -- & $\checkmark$ \\
\hline Final approval of article & $\checkmark$ & $\checkmark$ & $\checkmark$ & $\checkmark$ & $\checkmark$ & $\checkmark$ & $\checkmark$ & $\checkmark$ \\
\hline Statistical analysis & $\checkmark$ & $\checkmark$ & -- & -- & -- & -- & -- & -- \\
\hline $\begin{array}{l}\text { Contributed essential } \\
\text { reagents and tools }\end{array}$ & -- & -- & $\checkmark$ & $\checkmark$ & $\checkmark$ & $\checkmark$ & $\checkmark$ & $\checkmark$ \\
\hline
\end{tabular}

Publication history

EIC: Katalin Csiszar, University of Hawaii, USA.

Received: 14-Jan-2014 Revised: 19-Feb-2014

Accepted: 17-Mar-2014 Published: 21-Mar-2014

\section{References}

1. Boguniewicz M and Leung DY. Recent insights into atopic dermatitis and implications for management of infectious complications. J Allergy
Clin Immunol. 2010; 125:4-13; quiz 14-5. | Article | PubMed Abstract | PubMed Full Text

2. Cork MJ, Danby SG, Vasilopoulos Y, Hadgraft J, Lane ME, Moustafa M, Guy RH, Macgowan AL, Tazi-Ahnini R and Ward SJ. Epidermal barrier dysfunction in atopic dermatitis. J Invest Dermatol. 2009; 129:1892-908. | Article | PubMed

3. Metcalfe DD, Baram D and Mekori YA. Mast cells. Physiol Rev. 1997; 77:1033-7979. | Article | PubMed

4. Krakowski AC, Eichenfield LF and Dohil MA. Management of atopic dermatitis in the pediatric population. Pediatrics. 2008; 122:812-24. | Article | PubMed

5. Valdman-Grinshpoun $Y$, Ben-Amitai D and Zvulunov A. Barrier-restoring therapies in atopic dermatitis: current approaches and future perspectives. Dermatol Res Pract. 2012; 2012:923134. | Article | PubMed Abstract | PubMed Full Text

6. Stoeckli MR, McNeilly TN, Frew D, Marr EJ, Nisbet AJ, van den Broek $\mathrm{AH}$ and Burgess ST. The effect of Psoroptes ovis infestation on ovine epidermal barrier function. Vet Res. 2013; 44:11. | Article | PubMed Abstract | PubMed Full Text

7. Iddamalgoda A, Le QT, Ito K, Tanaka K, Kojima H and Kido H. Mast cell tryptase and photoaging: possible involvement in the degradation of extra cellular matrix and basement membrane proteins. Arch Dermatol Res. 2008; 300 Suppl 1:S69-76. | Article | PubMed

8. Zeghichi S, Kallithraka S and Simopoulos AP. Nutritional composition of molokhia (Corchorus olitorius) and stamnagathi (Cichorium spinosum). World Rev Nutr Diet. 2003; 91:1-21. | Article | PubMed

9. Matsuda H, Watanabe N, Geba GP, Sperl J, Tsudzuki M, Hiroi J, Matsumoto M, Ushio H, Saito S, Askenase PW and Ra C. Development of atopic dermatitis-like skin lesion with IgE hyperproduction in NC/Nga mice. Int Immunol. 1997; 9:461-6. | Article | PubMed

10. Yokoyama S, Hiramoto K, Fujikawa T, Kondo H, Konishi N, Sudo S, Iwashima M and Ooi K. Skin Hydrating Effects of Corchorus olitorius Extract in a Mouse Model of Atopic Dermatitis. J CosmetDermatolSci Appl. 2014. | Article

11. Suto H, Matsuda H, Mitsuishi K, Hira K, Uchida T, Unno T, Ogawa H and Ra C. NC/Nga mice: a mouse model for atopic dermatitis. Int Arch Allergy Immunol. 1999; 120 Suppl 1:70-5. | Article | PubMed

12. Kinet JP. The high-affinity IgE receptor (Fc epsilon RI): from physiology to pathology. Annu Rev Immunol. 1999; 17:931-72. | Article | PubMed

13. Galli SJ, Tsai M and Piliponsky AM. The development of allergic inflammation. Nature. 2008; 454:445-54. | Article | PubMed Abstract | PubMed Full Text

14. Suzuki H, Oomizu S, Yanase Y, Onishi N, Uchida K, Mihara S, Ono K, Kameyoshi $Y$ and Hide M. Hydrolyzed Konjac glucomannan suppresses IgE production in mice B cells. Int Arch Allergy Immunol. 2010; 152:12230. | Article | PubMed

15. Oomizu S, Yanase Y, Suzuki H, Kameyoshi $Y$ and Hide M. Fucoidan prevents $C$ epsilon germline transcription and NFkappaB p52 translocation for IgE production in B cells. Biochem Biophys Res Commun. 2006; 350:501-7. | Article | PubMed

16. Yoshikawa M, Shimada H, Saka M, Yoshizumi S, Yamahara J and Matsuda H. Medicinal foodstuffs. V. Moroheiya. (1): Absolute stereostructures of corchoionosides A, B, and C, histamine release inhibitors from the leaves of Vietnamese Corchorus olitorius L. (Tiliaceae). Chem Pharm Bull (Tokyo). 1997; 45:464-9. | PubMed

17. Leknes SG, Bantick S, Willis CM, Wilkinson JD, Wise RG and Tracey I. Itch and motivation to scratch: an investigation of the central and peripheral correlates of allergen- and histamine-induced itch in humans. $J$ Neurophysiol. 2007; 97:415-22. | Article | PubMed

18. Gschwandtner M, Purwar R, Wittmann M, Baumer W, Kietzmann M, Werfel T and Gutzmer R. Histamine upregulates keratinocyte MMP-9 production via the histamine H1 receptor. J Invest Dermatol. 2008; 128:2783-91. | Article | PubMed

19. Oboh G, Raddatz H and Henle T. Characterization of the antioxidant properties of hydrophilic and lipophilic extracts of Jute (Corchorus olitorius) leaf. Int J Food Sci Nutr. 2009; 60 Suppl 2:124-34. | Article | 
Yokoyama et al. Dermatology Aspects 2014,

http://www.hoajonline.com/journals/pdf/2053-5309-2-3.pdf

PubMed

20. Trouba KJ, Hamadeh HK, Amin RP and Germolec DR. Oxidative stress and its role in skin disease. Antioxid Redox Signal. 2002; 4:665-73. | Article | PubMed

21. Suzuki Y, Yoshimaru T, Inoue T, Niide $O$ and Ra C. Role of oxidants in mast cell activation. Chem Immunol Allergy. 2005; 87:32-42. | Article | PubMed

22. Horrobin DF. Essential fatty acid metabolism and its modification in atopic eczema. Am J Clin Nutr. 2000; 71:367S-72S. | PubMed

23. Kawamura A, Ooyama K, Kojima K, Kachi H, Abe T, Amano K and Aoyama T. Dietary supplementation of gamma-linolenic acid improves skin parameters in subjects with dry skin and mild atopic dermatitis. J Oleo Sci. 2011; 60:597-607. | PubMed

\section{Citation:}

Yokoyama S, Hiramoto K, Fujikawa T, Kondo H, Konishi N, Sudo S, Iwashima M and Ooi K. Topical application of Corchorus olitorius leaf extract ameliorates atopic dermatitis in NC/Nga mice. Dermatol Aspects. 2014; 2:3. http://dx.doi.org/10.7243/2053-5309-2-3 